\title{
Structure, Function and Regulation of Outer Membrane Proteins Involved in Drug Transport in Enterobactericeae: the OmpF/C - TolC Case
}

\author{
Muriel Masi ${ }^{1}$, Jean-Marie Pagès ${ }^{2,3, *}$ \\ ${ }^{1}$ CNRS-UMR 8619, Institut de Biophysique et de Biochimie Moléculaire et Cellulaire (IBBMC), Université Paris Sud, \\ Orsay, France \\ ${ }^{2} U M R-M D 1$, Université d'Aix-Marseille, IRBA, Marseille, France \\ ${ }^{3}$ COST Action BM0701 (ATENS), Brusells, Belgium
}

\begin{abstract}
Antibiotic translocation across membranes of Gram-negative bacteria is a key step for the activity on their specific intracellular targets. Resistant bacteria control their membrane permeability as a first line of defense to protect themselves against external toxic compounds such as antibiotics and biocides. On one hand, resistance to small hydrophilic antibiotics such as B-lactams and fluoroquinolones frequently results from the «closing » of their way in: the general outer membrane porins. On the other hand, an effective way out for a wide range of antibiotics is provided by TolC-like proteins, which are outer membrane components of multidrug efflux pumps. Accordingly, altered membrane permeability, including porin modifications and/or efflux pumps' overexpression, is always associated to multidrug resistance (MDR) in a number of clinical isolates.

Several recent studies have highlighted our current understanding of porins/TolC structures and functions in Enterobacteriaceae. Here, we review the transport of antibiotics through the $\mathrm{OmpF} / \mathrm{C}$ general porins and the TolC-like channels with regards to recent data on their structure, function, assembly, regulation and contribution to bacterial resistance.
\end{abstract}

Because MDR strains have evolved global strategies to identify and fight our antibiotic arsenal, it is important to constantly update our global knowledge on antibiotic transport.

Keywords: Antibiotics, Efflux pumps, Membrane permeability, Multidrug resistance, Porins.

\section{INTRODUCTION}

The outer membrane (OM) of Gram-negative bacteria constitutes the first permeability barrier that protects the cells against environmental stresses including chemical, biophysical and biological attacks [1]. Simultaneously, it allows the selective uptake of essential nutrients and the secretion of metabolic waste products. Regarding its biochemical structure and composition, the $\mathrm{OM}$ is a sophisticated organization of lipid and protein components. The OM is an asymmetric lipid bilayer in which phospholipids exclusively partition with the inner leaflet and lipopolysaccharide covers the outer leaflet [2]. The OM also contains proteins. These outer membrane proteins (OMPs), called porins, are characterized by a $\beta$-barrel structure and form water-filled channels for the passage of a large variety of hydrophilic molecules. Different types of porins have been characterized in Gram-negative bacteria and classified according to their activity, structure and regulation. These aspects have been discussed in various reviews [3-5]. It is also worth to note that OMPs' structure and assembly (mostly trimeric $\beta$-barrels) are conserved

*Address correspondence to this author at the UMR-MD1, Transporteurs Membranaires, Chimiorésistance et Drug Design, Faculté de Médecine, 27 Bd Jean Moulin, 13385 Marseille cedex 05, France; Tel: (33) 4913245 87; Fax: (33) 4913246 06; E-mail: jean-marie.pages@univmed.fr throughout all species of Proteobacteria, while the corresponding genomes have been predicted to encode a variable number of OMPs [6-8]. This may not only reflect a common evolution but also very well-adapted pathways to rule the influx of nutrients and the efflux of intracellular noxious compounds.

One of the bacterial strategies for drug resistance is to limit the intracellular access of an antibiotic via modification of membrane permeability. This strategy includes both influx and efflux of antibiotics (Fig. 1). $\beta$-lactams and fluoroquinolones are the two main classes of active antibiotics against Gram-negative bacteria. These are small and hydrophilic drugs that enter the cells via the general $\mathrm{OmpF} / \mathrm{C}$ porins. In this review, we point out recent clinical data that report bacterial strategies based on porin modifications to limit $\beta$ lactam influx: exchange in the type of porin expressed; change in the level of porin expression; mutations or modifications that impair the functional properties of the channel [1-9]. The prevalence of these strategies in MDR clinical isolates highlights the importance to understand the molecular bases of the antibiotic influx mechanism. In particular, advances in molecular modeling approaches are promising to study subtle porin-antibiotic interactions $[10,11]$. Such information could used to screen for antibiotics with enhanced diffusion properties through porins. 


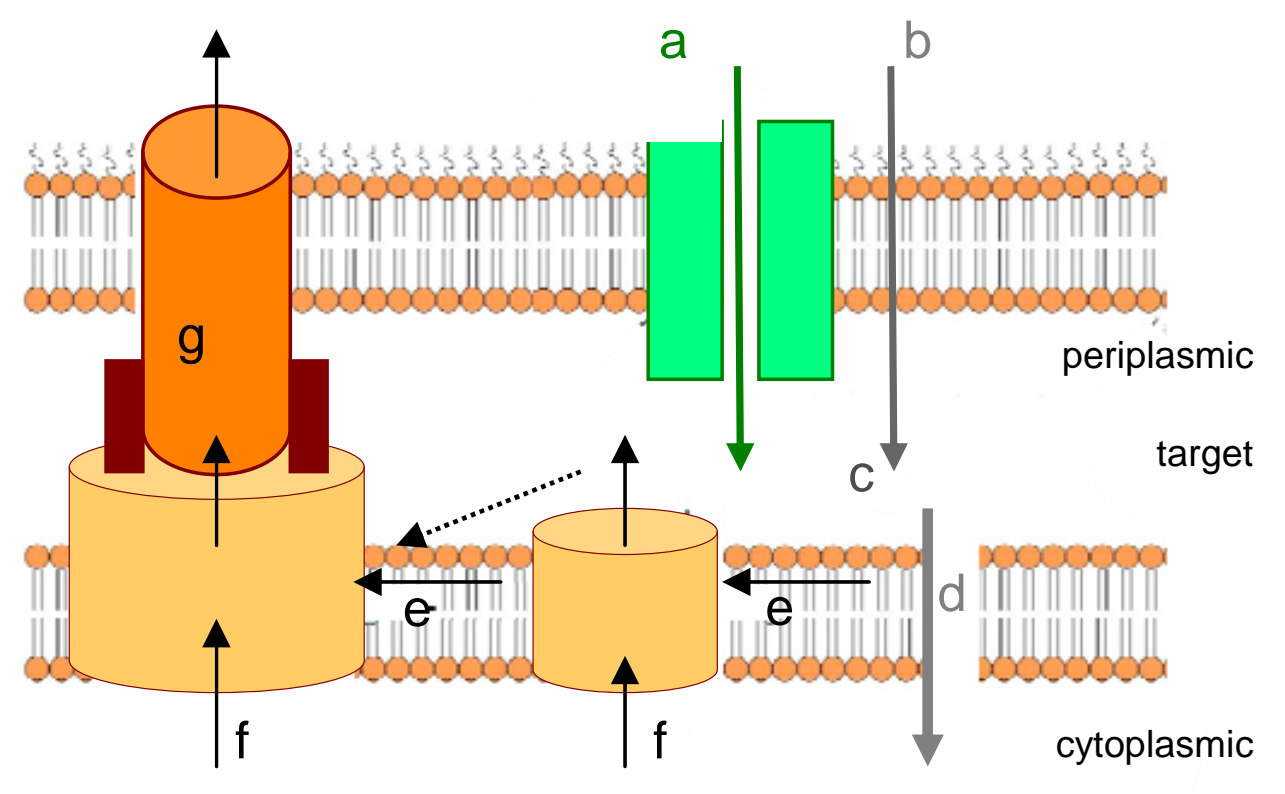

target

Fig. (1). Antibiotic transport through the membranes of Gram-negative bacteria (reproduced from [168]).

To be active against bacterium, an antibiotic needs a critical concentration threshold to inhibit the corresponding target. Using the concentration gradient, the influx is controlled by several elements: the antibiotic can permeate through the OM via porins (a, for hydrophilic molecules) or through the OM (b, for hydrophobic drugs). (c) represents the diffusion through the periplasmic space in which enzymatic inactivation may occur. Finally, the drug will pass the cytoplasmic / IM (d).

Regarding the efflux, the drug may be recognized and transported by active pump (e) or (f). The pump (e.g. AcrB) has to recruit the OM pore TolC (g), in addition it may conjointly acts with other pumps (e.g. MFS family). The success of a drug is given by the kinetics of all individual steps.

In addition to the influx problem, several recent reports have shown a significant increase in the dissemination of clinical strains with active antibiotic efflux [12]. Of concern is the polyspecificity of drug efflux transporters that confers MDR but also strengthens the resistance level to individual antibiotics due to other mechanisms (e.g. mutation of drug targets or production of degradation enzymes) $[1,13]$. In Gram-negative bacteria, multidrug efflux pumps share a tripartite organization that spans the entire cell envelop: an active drug transporter is located in the inner membrane (IM); an OMP of the TolC-like family form the exit conduct across the outer membrane; and a periplasmic protein mediates a functional link between the IM and the OM components [1]. The archetypical OMP TolC of E. coli can function with three types of IM transporter including the ATPbinding cassette (ABC)-type, the resistance-nodulationdivision (RND)-type and the major-facilitator (MF)-type. In this review, we will discuss the assembly, the mechanism of transport and the regulation of RND-type efflux pumps, which are the major contributors of MDR in Gram-negative bacteria. These data are of most importance for the design of efflux pump inhibitors (EPI) and restore the potency of current antibiotics $[14,15]$.

\section{CLASSICAL PORINS: THE OMPF/C FAMILY}

\subsection{Regulation}

In Enterobacteriaceae, porins represent a special class of OMPs that form water-filled channels through which hydrophilic solutes gain access into the bacterial cell [1,9]. In $E$. coli, the two general porins $\mathrm{OmpC}$ and $\mathrm{OmpF}$ are among the most abundant OMPs (about $10^{5}$ copies per cell) and serve as general pathways for the influx of small molecules (e.g. molecular weight under 600). They consist of three 16stranded $\beta$-barrels, each of which forms a channel that is restricted in the middle due to the inward folding of a loop (loop L3) [16].

The expression of E. coli porins has been extensively studied. In particular, the ompC and $о т p F$ genes are transcriptionally regulated by the two-component regulatory system OmpR-EnvZ [17,18]. EnvZ is a membrane-bound sensor kinase, although the environmental signal it detects is not known. OmpR is a cytosolic response regulator, which binds to the promoter region of the porin genes. Changes in medium osmolarity profoundly affect expression of OmpF and $\mathrm{OmpC}$ : OmpC is preferentially expressed in high osmo- 
larity, whereas OmpF expression is favored in low osmolarity [19]. Although the level of OmpR P in vivo has not been determined, it is presumed that the $[\mathrm{OmpR} \sim \mathrm{P}]$ increases with increasing osmolarity, promoting activation and then repression of ompF and activation of ompC. Other factors, including local anesthetics [20], $\mathrm{pH}$ [21], and nutrition limitation [22] also influence ompF and ompC transcription in an EnvZ/OmpR-dependent manner. Noteworthy, growth conditions where nutrient levels are high, such as in mammal intestinal tracts, favor the expression of $\mathrm{OmpC}$, which has a smaller channel than OmpF, thus limiting the influx of large and charged molecules such as bile salts and antibiotics. Conversely, OmpF will be the major porin under ex vivo growth conditions with nutritional deficiency, as its larger pore will allow efficient influx of nutrients.

Several studies also proved the role of the CpxA/CpxR two-component envelope stress response system in the regulation of the OmpF and OmpC expression [23-26]. Sigma E and CpxAR constitute the two major regulation pathways that control the envelop integrity $[27,28]$. Specifically, the CpxAR pathway is activated in response to several signals including $\mathrm{pH}$, osmolarity, defective LPS and overexpression of misfolded OMPs [28]. The CpxAR-mediated regulation of porin expression is complex. At the transcriptional level, the cytoplasmic response regulator $\mathrm{CpxR} \sim \mathrm{P}$ has been shown to bind directly the ompF and ompC promoters [24]. More recently, Misra and coll. found that the IM protein YqjB renamed MzrA - connects the CpxA/CpxR and EnvZ/OmpR regulatory systems [26]. In this pathway and in response to the activation of CpxAR, MzrA interacts directly with EnvZ, which, in turn, stabilizes OmpR P. Given that $\mathrm{CpxA} / \mathrm{R}$ and Env/OmpR sense different signals, their connection allows cells to adapt to diverse environmental changes [26,29]. To date, the influence of two-component regulatory systems on porin expression and MDR phenotype in clinical isolates is still poorly documented.

$\mathrm{OmpC}$ and $\mathrm{OmpF}$ are also subject to post-transcriptional regulation by small regulatory RNAs including MicF [30], MicC [31], IpeX [32], RseX [33], RybB [34], and CyaR [35] (see $[37,38]$ for reviews). A characteristic of these regulatory RNA molecules is that they prevent translation by base pairing with their target mRNAs in the region encompassing the ribosome binding site and start codon [36]. Briefly, MicF was first base-pairing regulatory RNA found in E. coli [30]. MicF is located upstream of the ompC promoter and inhibits the expression of OmpF by decreasing the levels of ompF mRNA. Under high osmolarity conditions, OmpR activates the expression of MicF, and thus intensify the inhibition of OmpF expression. In addition, MicF expression is regulated by transcription factors of AraC/XylS family - MarA, SoxS and Rob - that are involved in MDR phenotype. The ompNmicC organization is reminiscent to that of ompC-micF. MicC down-regulates the expression of OmpC [31]. IpeX was identified as a multicopy suppressor of the lethal and assembly-defective $\mathrm{OmpC}_{2 \mathrm{Cys}}$ [32]. Unlike $\mathrm{MicF}$ and $\mathrm{MicC}$, IpeX does not involve base-pairing with the ompC and $o m p F$ mRNAs. At last, porin expression is also regulated by several $\sigma^{\mathrm{E}}$-dependent small RNAs: RybB targets OmpC [34], RseX inhibits OmpA and OmpC [33], and CyaR shuts down OmpX expression [35]. Again, this would allow a strong and fine-tuned regulation of porin expression in response to different signals.

The study of porin expression in clinical isolates (type of porin expressed; level of expression; regulation and association to a resistant phenotype) is complex due to the number of genes and external factors involved. In Enterobacteriaceae, the Mar locus and RamA are the two major MDR regulatory pathways. Mutations in the corresponding genes induce the overproduction of efflux pumps and inhibit porin expression both directly and indirectly [39-41]. In addition, various compounds such as salicylate [42], chloramphenicol [43], imipenem [44] and tetracycline [43, 45] are able to activate these and other unknown MDR regulatory pathways $[46,47]$. This phenomenon has been observed when bacteria are grown in the presence of subinhibitory concentrations of drugs and in vivo during antibiotic treatment of infected patients. These mechanisms are reviewed in details in Davin et al. [13].

Concerning the emergence of a MDR phenotype, the final outcome of this complex and overlapping regulation is to reduce antibiotics' influx. This can be achieved via the selection of the type of porin expressed or a global decrease in porin expression level.

Some clinical isolates often express porin with small channel size to decrease their antibiotic susceptibility [9]. In a study on Klebsiella pneumoniae strains, some isolates lack the large diffusion channels OmpK35 (OmpF-type porin) and OmpK36 (OmpC-type porin), but express OmpK37 that forms a smaller pore [48]. This porin exhibits some similarities with OmpN of E. coli and OmpS2 of Salmonella enterica serovar Typhi, which are normally quiescent in laboratory growth conditions. The presence of OmpK37 combined with the absence of OmpK35 and OmpK36 lead to a drastic increase in the minimal inhibitory concentrations (MICs) of cefotaxime and cefoxitin, but not of carbapenems indicating that these compounds might still be able to penetrate through OmpK37 channel. More recently, our group characterized two porins of Providencia stuartii, named OmpPst1 and OmpPst2. As the bacteria were grown in the presence of $\beta$ lactam antibiotics, resistant derivatives were deficient in OmpPst1 [49]. Interestingly, OmpPst2 exhibits a higher conductance (e.g. a larger channel size) but a lower antibiotic flux than OmpPst2.

Clinical studies have reported the evolution of porin expression and antibiotic resistance in Enterobacter aerogenes strains collected from patients under imipenem therapy [50]. First, it was worth to note that resistant isolates emerged very rapidly (after 5 days of treatment). Second, that data clearly showed the progressive decrease in Omp36 (OmpC-type porin) expression that correlates with progressive increase in resistance towards $\beta$-lactams. The simultaneous overexpression of efflux pump(s) in these resistant isolates suggests a complex regulation that coordinates both influx and efflux. This scenario was reproduced when a susceptible strain of E. aerogenes was grown in the presence of imipenem and was shown to involve the Mar locus: derepression of the activator MarA triggered a cascade of downstream events that resulted in global change of membrane permeability including down-regulation of porin synthesis and overexpression of efflux pump components. 
Conflicting reports exist regarding the role of OMPs in the invasion and/or virulence of pathogenic bacteria. Deletion of ompC in an E. coli strain involved in Crohn's impaired its abilities to adhere to and to invade intestine cells [51], indicating a possible role of OmpC as an adhesin or an invasin, and mutants of an enterotoxigenic E. coli strain deleted for ompC and ompF are attenuated in virulence in human volunteers [52]. More recently, MDR clinincal isolated of $K$. pneumoniae and E. aerogenes with reduced porin expression appeared to be less virulent animal models (e.g. mouse and Caenorhabditis elegans) [53-55]. In particular, porin deficiency that appear during antibiotic exposure would generate isolates with high level of antibiotic resistance but reduced fitness to colonize their host $[55,56]$.

\subsection{Porin Assembly}

OMPs are synthesized in the cytoplasm as precursors with an N-terminal cleavable signal sequence. In most cases, precursors are targeted to the IM SecYEG translocon by the cytoplasmic chaperone $\mathrm{SecB}$ and the molecular ATPase motor SecA [57]. Following IM translocation and cleavage of the signal sequence, OMPs are released into the periplasm where they are maintained in a conformation competent for assembly by several factors [58]. These include the general chaperone Skp, the major peptidyl prolyl cis-trans isomerase SurA, the periplasmic protease/chaperone DegP [59], and lipopolysaccharide [60]. From here, the mechanism for targeting and assembling OMPs was largely unknown until Omp85 of Neisseria meningitis was found essential for growth and conservation of normal levels of correctly folded and assembled $\beta$-barrel proteins in the OM [61]. Since then, Omp85 renamed BamA - for $\beta$-barrel assembly machinery protein $\mathrm{A}$-, homologues have been identified in all genomes of Gram-negative bacteria [62, 63]. In Enterobactericeae, assembly of OMPs is assisted by the BamABCDE complex comprised of five proteins, in which BamBCDE are 4 accessory lipoproteins $[64,65]$. In $E$. coli and $N$. meningitis, both BamA and BamD are essential $[64,66]$. BamA contains two domains: an N-terminal domain that is located in the periplasm and folds as 5 POTRA (polypeptide translocation associated) motifs and a $\mathrm{C}$-terminal domain that crosses the $\mathrm{OM}$ as a $\beta$-barrel [67]. The POTRAs play a crucial role as they are contact points for the Bam lipoproteins, periplasmic chaperones, and incoming OMP polypeptides. Ultimate membrane insertion likely involves other regions of BamA [67-71]. Recent works have provided clues for a possible mechanism in which a conserved long loop that folds inside the $\beta$-barrel undergoes conformational changes upon substrate recognition and drags the substrate to its final destination [72-75].

During last decade, our understanding of OMP biogenesis has considerably increased (see [57] for a review). However, a lot of details - such as the precise interactions of the Bam proteins with each other and with substrates; kinetics of OMPs' folding, assembly and membrane insertion - are still lacking. These points are of special interest for many reasons. First, all steps in OMP biogenesis are tightly coupled by numerous and sometimes overlapping regulatory networks: envelop stress responses control the levels the expression of genes that encode chaperones, Bam proteins, periplasmic proteases and the expression of small regulatory
RNAs. Only a few studies have analyzed envelop stress responses upon antibiotic exposure and their effects on both porin expression and MDR [45,76]. Second, the fact that the Bam complex is conserved and essential in all Gramnegative bacteria suggests it could be an attractive target to design therapeutic molecules with mechanisms of action. Recently, Srinivas et al. reported the synthesis of a new family of peptidomimetic antibiotics based on the antibacterial peptide protegin 1 [77]. These molecules target the function of LptD, which together with LptE forms the essential complex that assembles LPS into the OM [78,79], and showed strong antimicrobial activity against Pseudomonas aeruginosa.

\subsection{Porin-mediated Antibiotic Transport and Resistance}

The crystal structure of several porins have been determined [16,80-82]. A key feature is a conserved loop (L3) that folds back into the channel to form the so-called constriction zone orthe eyelet. In $\mathrm{OmpF}$ of $E$. coli, this region determines the channel size to approximately $7 \AA \times 11 \AA$ and represents the bottleneck for diffusion. In addition to the spatial constriction, this region is also characterized by a strong transversal electric field as negatively charged amino acids (D113, E117) of loop L3 are facing positively charged residues (K16, R42, R82 and R132). As a result, mutations in this region in Omp36 of E. aerogenes [83,84], OmpK36 of K. pneumonia [85], OmpF and OmpC of E. coli undoubtedly affect antibiotic transport and strain susceptibility [8690] (see below for details).

Our understanding of antibiotic transport bacterial porins has been greatly enhanced by multidisciplinary approaches that combine in vitro and in vivo experiments and simulations. The electrophysiological studies of porins have been largely discussed in recent reviews [3,9,10]. Briefly, the method consists in the reconstitution of purified proteins into planar lipid bilayers; ion-current measurements provide structural and functional characteristics such as conductance (e.g. pore size), ion selectivity and voltage-dependent closure. Recent development of this technique allowed the detailed analysis of antibiotic transport across porins at the single molecular level with measurements of affinity and flux of antibiotic molecules into the porins' channel [91-93]. Molecular modeling has also proven to be a powerful tool to complement experimental data. Recent simulations pinpointed the specific interactions between antibiotics and key residues in the porin channel[11,94-97]. Typically, diffusion efficacy depends on multiple electrostatic interactions, hydrogen bonds and hydrophobic interaction that engage chemical groups on the antibiotic and amino acids of the constriction zone of the porin. Consistently, the D113A substitution results in a significant increase in the ampicillin, cefoxitin, and ceftazidime susceptibility [96] and simulations illustrated the role of this residue in the screening molecules translocating across OmpF [11]. Together, studies that help to decipher antibiotic transport are of major importance to design new drugs that would efficiently escape the constriction zone for optimal permeation across wild-type and mutated porins.

In the last twenty years, the extensive use of new cephalosporins with efficient diffusion and enhanced resistance 
towards inactivating enzymes lead to the selection of Gramnegative bacteria with modifications in membrane permeability. This is best exemplified by the observation that mutations in porins of resistant clinical isolates exclusively and constantly target amino acids of the loop L3 [9]. Clinical isolates of E. aerogenes with high-level $\beta$-lactam resistance express Omp36 (OmpC-type porin) that carried the substitution G112D [83,94]. This position is located in loop L3. The homologous mutation G119D in E. coli OmpF narrows the size of the channel as the large side chain of Asp protrudes into the channel lumen, and confers a drastic reduction in $\beta$ lactam susceptibility [87]. Consistently, the Omp36 ${ }^{\mathrm{G} 112 \mathrm{D}}$ mutant of E. aerogenes was characterized by a 3 -fold decrease in ion conductance and a significant decrease in cephalosporin sensitivity (e.g. MICs of cefotaxime, cefpirome, cefepime and ceftazidime were 7 to 9 fold higher in the clinical isolate as compared to that in a sensitive reference strain) and a cross resistance to carbapenems [84]. In another study, a series of antibiotic resistant $E$. coli isolates were isolated from a patient during serial treatment with various antibiotics. The sequence of $\mathrm{OmpC}$ changed at three different positions during treatment generating a total of seven variants [98]. These isolates exhibited progressive increased levels of antibiotic resistance and expressed OmpC with two amino acid substitutions (D18E and S274F) which might influence antibiotic influx. The final and most resistant isolates, which were obtained after carbapenem treatment, showed reduced levels of OmpC. These are the only two examples of clinical selection of mutated porins in the Enterobacteriaceae during antibiotic treatment. Therefore, one can expect that the occurrence of such mutations might be underestimated. Finally, some bacterial species, such as Pseudomonas aeruginosa, are intrinsically more resilient to antibiotic treatments, because of the low abundance of nonspecific porins, combined with numerous drug efflux mechanisms [9].

\section{THE EFFLUX PORINS: THE TOLC-LIKE PRO- TEIN FAMILY}

TolC is a minor but functionally important OMP in $E$. coli, E. coli tolC mutants were originally isolated with the phenotype of resistance to colicin E1 [99]. Because these mutants still bind the colicin as well as wild type bacteria, they were considered to be tolerant rather than resistant. Over the years, TolC has been shown to be a multifunctional protein involved in secretion of toxins $[100,101]$ and efflux of a wide range of xenobiotics including antibiotics, biocides, bile salts and organic solvents $[1,102]$. Therefore, TolC plays a central role in both the emergence of MDR phenotypes of clinical isolates and the virulence of pathogenic species. It also serves as a cell-surface receptor for a specific bacteriophage [103]. Several publications have recently reported a significant involvement of TolC in the bacterial virulence and pathogenesis regarding various Gram-negative pathogens including Enterobacter, Borrelia, Salmonella, Vibrio, Legionella, Francisella [104-111].

TolC-dependent transport systems exhibit a common three-component organization that spans the inner and outer membranes, bypassing the periplasm. This requires TolC to interact and function with proteins located in the IM: an active transporter that belongs to the ABC-, RND- or MFS- type transporter/pump and a periplasmic adaptor anchored in the IM.

TolC family proteins are ubiquitous among Gramnegative bacteria [112]. Enterobacteriaceae contain a single tolC gene - of which the deletion leads to a pleiotropic phenotype. At the opposite, genomes of other bacteria such as $P$. aeruginosa encode 18 TolC-like proteins [113], which can be divided into two distinct subfamilies whether they are involved in protein secretion (AprF subfamily) or multidrug efflux (OprM subfamily) functions. Substrate specificity relies on the IM transporter. TolC is able to function with the majority of IM transporters, thus explaining it can adapt a wide range of substrates. This is consistent with that tolC is transcribed independently of its IM partners while secretion and efflux operons in other species encode the three protein components.

In this review, we will briefly describe the assembly and the mechanism of antibiotic transport of TolC-dependent efflux pumps, focusing on those of medical importance.

\subsection{Structure and Pore-forming Properties of TolC-like Proteins}

Several high-resolution structures of TolC-like proteins have now been solved including that of the archetypical $E$. coli TolC, the E. coli OMP of a heavy metal pump CusC, P.aeruginosa OprM, and Vibrio cholerae VceC [114-117]. Despite very low sequence similarity between these proteins, their overall structures are very similar and unique among OMPs [118]. Three TolC protomers assemble to form a single conduit called a 'channel-tunnel' comprising a $40-\AA \AA$ long $\beta$-barrel anchored in the OM (the channel domain), prolonged by a $100-\AA \AA$ long $\alpha$-helical barrel that extends into the periplasm (the tunnel domain), and a mixed $\alpha / \beta$ equatorial domain [114]. The three TolC protomers each contribute $4 \beta$-strands to form the single 12-stranded OM $\beta$-barrel. This strongly contrasts with porins, in which the $\beta$-barrel is formed by a single subunit. The periplasmic $\alpha$-helical barrel comprises 12 coiled-coil $\alpha$-helices ( 4 from each protomer) packing antiparallel with a left-handed twist. TolC provides a huge water-filled channel with a volume of $43,000 \AA^{3}$ that allows the passage of large and partially folded proteins such as the $160 \mathrm{kDa} \alpha$-hemolysin. TolC is constitutively open to the external medium with an average accessible interior diameter of $19.8 \AA$ throughout the channel and most of the tunnel [114]. In addition, the channel TolC is not occluded by an inside loop, such as loop L3 that constricts $\beta$-barrel of the non-specific porins $\mathrm{OmpF}$ and $\mathrm{OmpC}$, or a plug domain, such as the ones that gate secretins [119] or close the $\beta$ barrel of the siderophore transporters FhuA and FepA [120, 121]. Therefore, one can assume that opening of the TolC pore must be tightly regulated to restrict the release of the periplasmic content and the entry of nonpermating extracellular toxins. The periplasmic entrance is the sole constriction of TolC: in the lower half of the tunnel, three of the six pairs of $\alpha$-helices form a conventional coiled coils that bend inward (the inner coils $\mathrm{H} 7 / \mathrm{H} 8$ ) to narrow the diameter of the pore to only $3.9 \AA$. This is reflected by the small conductance (e.g. $80 \mathrm{pS}$ ) of TolC and homologues reconstituted in planar lipid bilayers [122-124]. The periplasmic entrance of TolC must open to allow drug efflux and protein secretion. 
An allosteric iris-like mechanism has been proposed involving a realignment of the inner pair of coiled-coil helices $(\mathrm{H} 7 / \mathrm{H} 8)$ of each TolC monomer to the outer pair $(\mathrm{H} 3 / \mathrm{H} 4)$ [125]. The close conformation of TolC is stabilized by a circular network of inter- and intra-molecular salt bridges and hydrogen bonds that constrain the inner helices at the periplasmic entrance. Consistently, mutations of key residues can either lock or widen TolC aperture up to a 10-fold increase in conductance $[125,126]$. As the open configuration is unstable in vitro, it may be stabilized by interactions with the inner membrane transporter and/or adaptor protein in vivo (see below for in vivo and in vitro evidences).

Finally, it has been proposed that biochemical characteristics such as charge distribution and ion selectivity could facilitate or impede substrate movement across the channel of TolC-like proteins. However, soaking of high concentrations of copper or silver ions in CusC crystals did not result in metal binding, suggesting the absence of specific substrate binding sites, since [117]. Therefore, it seems unlikely that TolC-like proteins contribute to the drug specificity of efflux pumps.

\subsection{TolC Assembly}

Studies from the Misra's laboratory showed that the unique structure of TolC reflects a unique assembly pathway. Like other OMPs, TolC is synthesized in the cytoplasm and transported across the IM via the Sec machinery. Then, the mature TolC polypeptide navigates in the periplasm as a soluble unfolded intermediate as suggested by its sensitivity to proteinase $\mathrm{K}$ degradation [127]. Studies on TolC assembly-defective mutants have also shown an ordered TolC assembly pathway, in which unfolded mature monomers are converted to folded monomers that oligomerize into a stable trimeric species [127]. The correct folding of the monomers is achieved by various intramolecular interactions. However, unlike other OMPs, none of the assembly steps of TolC is affected by known folding factors such as the periplasmic chaperones SurA, Skp and LPS [127]. Moreover, a signal sequence-less TolC is able to fold and trimerize in the cytoplasm of $E$. coli into a conformation similar to that of the OM-localized protein [128]. This particular behavior is attributable to the large soluble $\alpha$-helical domain of TolC that accounts for $\sim 70 \%$ of its structure [114]. Finally, the essential proteins BamA and BamD are required for the final assembly and membrane insertion of the majority of $\beta$-barrel OMPs, including TolC [66, 129]. Consistently, $\beta$-barrel OMPs such as OmpF and LamB are dependent on BamA POTRA 1 while TolC is not. The two assembly pathways likely merge at a later step, presumably during membrane insertion.

Compared to TolC, OprM and all other OMPs involved drug efflux are modified by acylation and have an extension of approximately 20 residues at their $\mathrm{N}$-terminus.

So far, data show that $\beta$-barrel OMPs and lipoproteins are transported to the OM via the Bam or the Lol pathways, respectively [130]. All TolC homologues share a common structure with a $\beta$-barrel domain that anchor the protein into the OM. Therefore, the physiological role of a dual membrane anchor found only in efflux proteins is not clear. Previous studies with $P$. aeruginosa OprM and E. aerogenes
EefC showed that the lipid moiety is not needed for protein localization in the $\mathrm{OM}$ or function in antibiotic efflux $[131,132]$. Therefore, important future issues are to answer the biogenesis pathway of TolC-like lipoproteins and explore the possible connections between the Bam and the Lol systems for transport and membrane insertion of this specific class of OMPs.

\subsection{Efflux Pumps Structure and TolC Channel-opening}

As mentioned above, the structure of TolC suggests a possible mechanism for drug transport [114]. First, the extended periplasmic domain of TolC was thought to dock periplasmic adaptors and IM transporters. This has been confirmed by several in vivo experimental data [133-139] (see below). Second, because the periplasmic entrance of TolC and homologues is tightly closed in its resting state, functional interactions with cognate partners are required to trigger the opening of TolC. In particular, a network of constraining bonds at the periplasmic entrance involves 4 key residues: T152, D153, Y362 and R367 [114,125]. The intraprotomer bond Y362-D153 tethers the inner coiled-coil $\mathrm{H} 7 / \mathrm{H} 8$ to the outer coiled-coil $\mathrm{H} 3 / \mathrm{H} 4$, while interactions R367-D153 and R367-T152 between adjacent protomers link helix $\mathrm{H} 8$ to helix H4. Two independent groups have recently reported the crystal structures of mutant TolC in which these bonds were disrupted, revealing open state conformations $[140,141]$. The Koronakis's group solved the structures of $\mathrm{TolC}^{\mathrm{R} 367 \mathrm{~S}}$ where the inter-protomer bonds are disrupted and $\mathrm{TolC}^{\mathrm{R} 367 \mathrm{~S}, \mathrm{Y} 362 \mathrm{~F}}$ where the intra-protomer bond is also lost [141]. Abolition of the inter-protomer bonds in TolC ${ }^{\mathrm{R} 367 \mathrm{~S}}$ permitted a large realignment of the inner coiled-coil helix H7 while H8 stayed mostly static. Moreover, the channel seemed to remain partially closed by a second constriction at the position of D374. Completed opening was achieved upon the additional disruption of the intra-protomer bond: in $\mathrm{TolC}^{\mathrm{R} 367 \mathrm{~S} \text {, Y362F }}$ the inner coiled-coil helix H8 is moved outward and the D374 constriction is dilated, establishing a wide opening to $\sim 50 \AA^{2}$. The magnitudes of the TolC opening in these structures are consistent with electrophysiological data [125]. On the other hand, Bravo et al. solved the structure of a similar double mutant $\mathrm{TolC}^{\mathrm{R} 367 \mathrm{E}, \mathrm{Y} 362 \mathrm{~F}}$ in which all links mentioned above were also abolished but showed modest opening [140]. It has been proposed that crystals solved at non physiological $\mathrm{pH}$ could explain the differences observed between the two structures [141].

A massive amount of studies had been carried out to identify residues and regions important for functional interactions between TolC and its cognate efflux partners, namely AcrA (the periplasmic adaptor) and AcrB (the RND-type efflux pump). The open TolC structures help to refine the common pump assembly model in which TolC and AcrB directly interact tip-to-tip [142] and the coiled-coil helices of AcrA $[143,144]$ fit into the intra-protomer groove formed between the inner $(\mathrm{H} 7 / \mathrm{H} 8)$ and the outer $(\mathrm{H} 3 / \mathrm{H} 4)$ coiled-coil helices of TolC $[145,146]$. Very recently, another docking model has been proposed in which the adaptor MexA engages a tip-to-tip interaction with the OM protein OprM [147]. Structural data showed that AcrB, which consists of three protomers, goes through a three-step cycle of conformational changes during drug efflux $[148,149]$. In this cycle, each protomer has a different conformation corresponding to 
one of the three functional steps of the efflux cycle (e.g. drug access, drug binding and drug extrusion) [150]. However, AcrB conformational changes did not involve regions of direct interaction with TolC, suggesting that TolC opening relies exclusively in rearrangements transmitted to and via AcrA. Consistent with this idea, mutations that suppress TolC defective mutants are constantly found in AcrA $[133,138]$. Whether TolC follows the AcrB-rotating mechanism is still under debate [133,141].

\subsection{Efflux Pump-mediated Antibiotic Resistance and Regulation of TolC in Clinical Isolates}

tolC is a target of the marA/soxS/rob regulon $[102,151]$ which includes over 40 genes that are involved in MDR $[152,153]$. These genes are transcriptionally activated by three paralogous proteins, MarA, SoxS and Rob [102,151] that bind degenerate nucleotide sequences known as Mar-, Rob- or Sox-boxes [154]. E. coli marA is part of the marRAB operon of which the expression is controlled by the marO operator. In E. coli, regulation of marA is provided through the repressor MarR.

Zhang et al. have identified four tolC promoters ( $p 1-p 4)$ that respond to several environmental signals [155]. The $p 1$ promoter provides constitutive expression under laboratory conditions. The $p 2$ promoter is responsive to the twocomponent regulatory systems to EvgAS and PhoPQ [156]. Concomitant with upregulation of tolC, EvgA upregulated several efflux genes (acrAB, emrKY, mdfA and yhiUV) and showed increased antibiotic resistance that was fully dependent on TolC but only partially dependent on AcrA. The environmental signal for EvgAS is not known but PhoPQ is activated by low $\mathrm{pH}$ and low $\mathrm{Mg}^{2+}$ concentrations [157]. The $p 3$ and $p 4$ promoters are activated by MarA, SoxS and Rob, with each activator being regulated by different environmental signals. marA and soxS expression can be increased by treating cells with salicylate [158] and paraquat [159], respectively, and the activity of Rob can be increased by treatment with $2,2^{\prime}$-dipyridyl, bile salts or decanoate $[160,161]$. These three activators also upregulate $a c r A B$ and other genes which are critical for increased multidrug and superoxide resistances whereas EvgAS and PhoPQ regulate different sets of genes. Salmonellae, K. pneumonia and E. aerogenes but not $E$. coli also express another transcriptional activator of the XylS/AraC family called RamA that upregulates TolC and AcrAB $[40,41,162,163]$. The multiplicity of tolC transcriptional regulatory elements likely reflects the need to adjust TolC level and function (drug efflux, protein transport, cell adherence...) in different environments.

tolC-null mutants exhibit pleiotropic phenotypes including high susceptibility to xenobiotics. Noteworthy, the loss of tolC has a more severe phenotype than that of acrAB, confirming that TolC associates with other efflux pumps [164].

In clinical isolates, overexpression of efflux genes is concomitant to MDR and usually arises from spontaneous mutations in the marR or ramR repressors causing derepression of MarA and RamA, respectively. High level of antibiotic resistance is largely attributable to active efflux by the AcrAB-TolC system [12]. The functions of MDR regulators are well documented. Data usually show the effect of inacti- vation of a repressor, inactivation or overexpression of an activator on the transcriptome of a susceptible reference strain. However, most of the studies dealing with clinical isolates only reports changes in $a c r A B$ expression using RTPCR or immunoblotting techniques. Surprisingly, a recent study suggested no correlation between overproduction of $a c r A B$ and tolC [165], while these loci are both targets for MDR transcriptional activators such as MarA and RamA. 24 susceptible isolates and 36 resistant isolates with different MICs to fluoroquinolones were analyzed. Among the resistant isolates, 22 and 25 showed significant overexpression of acrA and acrB, respectively, though only 3 overexpressed tolC. These findings suggest a different regulation between tolC and acr $A B$ promoters. Moreover, TolC levels do not seem to be limiting. Alternatively, one cannot exclude the contribution of regulatory pathways that would specifically target tolC or acrAB.

\section{CONCLUSION}

It is important to mention that, despite some differences in the molecular structure and function, general porins and TolC share some common regulatory pathways. The tight regulation of the expression of these OMPs is now extensively documented in clinical isolates and the "Control of In and Out" has been discussed in several papers [1,13,14].

MarA acts as a master regulator of the expression of porin genes and tolC in E. coli and several other Enterobacteriaceae $[13,153,166,167]$. SoxS, another transcriptional regulator, is induced by oxidative stress and can activate MarA triggering the resistance cascade [173]. It is worthwhile to mention that some Gram-negative bacteria, such as Enterobacter, Klebsiella, Salmonella species, exhibit an additional global regulator, RamA. It plays a key role in controlling both porin and TolC expression directly or via the MarA cascade [13]. This joint regulation of uptake and efflux actively contribute to the tight and efficient control of intracellular accumulation of antibacterial agents inside the bacterium. This point is especially important : the polyspecificity of bacterial efflux transporters confers a general decrease of antibiotic susceptibility that can favor the acquisition of additional mechanisms of resistance towards antibacterial molecules such as mutation of antibiotic targets or expression of enzymes that modify antibiotics (e.g. ßlactamases) and also reinforces the effects of these acquired mechanisms [12]. A recent study dissected the respective role of Mar-Sox-Rob in controlling porin expression in $E$. coli [39]. Moreover, the heterogeneity of bacterial population face with drug attack may reflect the level of intracellular concentration of active antibiotic and can explain some variation observed in resistance level and the population adaptation [169]. It has been recently demonstrated that the over-expression of the AcrAB-TolC pump is an important prerequisite for the selection of fluoroquinolone resistant mutants that present mutated targets (DNA gyrase) in various Gram-negative bacteria described in severe human diseases [170-172].

The influence of OMPs such as porins and TolC in the balance between resistance and fitness cost in resistant isolates is still debated [53-56]. Although it is true that Gramnegative bacteria need general porins for sufficient uptake of 
nutrients, ions, etc [1], several isolates exhibit porin defects after antibiotic therapy, which impairs the penetration of drugs, such as B-lactams and fluoroquinolones [9]. It is also clear that LPS alterations that can induce large reorganization of the OM structure and alterations of the functional assembly of OM components is also a heavy sword of Damocles for the bacterial growth and competitiveness in an open space when the antibiotic pressure disappears[13,173175].

The level of intrabacterial accumulation of antibiotics on the susceptibility profile represents a key step in the development of novel treatment strategies for combating resistant bacteria. Consequently, several ways and means of increasing the intracellular accumulation, e.g. facilitating uptake or blocking the drug pumping out of the cell, are currently explored by several teams (see [176] for a recent review ). To conclude, it is interesting to note that today, with the increasing number of MDR isolates, several papers propose the re-use of an old antibiotic belonging to polymyxin group, colistin or the use of natural compounds to permeabilize the bacterial membrane (for recent reviews see [176-178]). The use of these "adjuvants" in combination with usual antibiotics could provide rapid penetration of the combined antibiotic, therefore ensuring an increase of intracellular concentration despite the OM barrier (porin defect and/or effux activity).

\section{CONFLICTS OF INTEREST}

The authors confirm that this article content has no conflicts of interest.

\section{ACKNOWLEDGEMENTS}

This study was supported by the Service de Santé des Armées, by the Université de la Méditerranée, by ANR-11BS07-019 'IBEF' and partly by COST Action BM0701 (ATENS).

\section{ABBREVIATION LIST}

$\begin{array}{lll}\text { OMP } & =\text { Omp, outer membrane protein } \\ \text { MDR } & =\begin{array}{l}\text { multidrug resistance, multidrug } \\ \text { resistant }\end{array} \\ \text { IM } & = & \text { inner membrane } \\ \text { OM } & \text { outer membrane } \\ \text { ABC transporter } & \text { ATP-binding cassette transporter- } \\ & = & \text { type }, \\ \text { RND } & = & \text { thajo resistance-nodulation-division } \\ \text { MF } & = & \text { efflux pump inhibitor } \\ \text { EPI } & = & \text { lipopolysaccharide } \\ \text { LPS } & = & \text { real-time PCR } \\ \text { RT-PCR } & \end{array}$

\section{REFERENCES}

[1] Nikaido H. Molecular basis of bacterial outer membrane permeability revisited. Microbiol Mol Biol Rev 2003; 67: 593-656.
[2] Silhavy TJ, Kahne D, Walker S. The bacterial cell envelope. Cold Spring Harb Perspect Biol 2010; 2:a000414.

[3] Delcour AH. Outer membrane permeability and antibiotic resistance. Biochim Biophys Acta 2009; 1794: 808-16.

[4] Fairman JW, Noinaj N, Buchanan SK. The structural biology of $\beta$ barrel membrane proteins: a summary of recent reports. Curr Opin Struct Biol 2011; 21: 523-31.

[5] Aguilella VM, Queralt-Martín M, Aguilella-Arzo M, Alcaraz A. Insights on the permeability of wide protein channels: measurement and interpretation of ion selectivity. Integr Biol (Camb) 2011; 3: 159-72.

[6] Pagès J.-M. Role of bacterial porins in antibiotic susceptibility of Gram-negative bacteria. In: Benz R, Ed. Bacterial and eukaryotic porins: Structure function and mechanism. Weinheim: Wiley-VCH 2004; pp. 41-59.

[7] Nguyen TX, Alegre ER, Kelley ST. Phylogenetic analysis of general bacterial porins: a phylogenomic case study. J Mol Microbiol Biotechnol 2006; 11: 291-301.

[8] Gatsos X, Perry AJ, Anwari K, et al. Protein secretion and outer membrane assembly in Alphaproteobacteria. FEMS Microbiol Rev 2008; 32: 995-1009.

[9] Pagès J.-M, James CE, Winterhalter M. The porin and the permeating antibiotic: a selective diffusion barrier in Gram-negative bacteria. Nat Rev Microbiol 2008; 6: 893-903.

[10] Ceccarelli M, Ruggerone P. Physical insights into permeation of and resistance to antibiotics in bacteria. Curr Drug Targets 2008; 9: 779-88.

[11] Hajjar E, Bessonov A, Molitor A, et al. Toward screening for antibiotics with enhanced permeation properties through bacterial porins. Biochemistry 2010; 49: 6928-35.

[12] Nikaido H, Pagès JM. Broad-specificity efflux pumps and their role in multidrug resistance of Gram-negative bacteria. FEMS Microbiol Rev 2012; 36: 340-63.

[13] Davin-Regli A, Bolla JM, James C, et al. Membrane permeability and regulation of drug "influx and efflux » in enterobacterial pathogens. Curr Drug Target 2008; 9: 750-9.

[14] Li XZ, Nikaido H. Efflux-mediated drug resistance in bacteria: an update. Drugs 2009; 69: 1555-623.

[15] Pagès JM, Amaral L. Mechanisms of drug efflux and strategies to combat them: challenging the efflux pump of Gram-negative bacteria. Biochim Biophys Acta 2009; 1794: 826-33.

[16] Cowan SW, Schirmer T, Rummel G, et al. Crystal structures explain functional properties of two E. coli porins. Nature 1992; 358: 727-33.

[17] Pratt LA, Hsing W, Gibson KE, Silhavy TJ. From acids to osmZ: multiple factors influence synthesis of the $\mathrm{OmpF}$ and $\mathrm{OmpC}$ porins in Escherichia coli. Mol Microbiol 1996; 20: 911-7.

[18] Mizuno T, Mizushima S. Signal transduction and gene regulation through the phosphorylation of two regulatory components: the molecular basis for the osmotic regulation of the porin genes. Mol Microbiol 1990; 4: 1077-82.

[19] van Alphen W, Lugtenberg B. Influence of osmolarity of the growth medium on the outer membrane protein pattern of Escherichia coli. J Bacteriol 1977; 131: 623-30.

[20] Villarejo M, Case CC. envZ mediates transcriptional control by local anesthetics but is not required for osmoregulation in Escherichia coli. J Bacteriol 1984; 159: 883-7.

[21] Heyde M, Portalier R. Regulation of major outer membrane porin proteins of Escherichia coli K12 by pH. Mol Gen Genet 1987; 208: $511-7$.

[22] Liu X, Ferenci T. Regulation of porin-mediate outer membrane permeability by nutrient limitation in Escherichia coli. J Bacteriol 1998; 180: 3917-22.

[23] Pogliano J, Lynch AS, Belin D, Lin EC, Beckwith J. Regulation of Escherichia coli cell envelope proteins involved in protein folding and degradation by the Cpx two-component system. Genes Dev 1997; 11: 1169-82.

[24] Batchelor E, Walthers D, Kenney LJ, Goulian M. The Escherichia coli CpxA-CpxR envelope stress response system regulates expression of the porins ompF and ompC. J Bacteriol 2005; 187: 5723-31. Price NL, Raivio TL. Characterization of the Cpx regulon in Escherichia coli strain MC4100. J Bacteriol 2009; 191: 1798-815.

[26] Gerken H, Leiser OP, Bennion D, Misra R. Involvement and necessity of the Cpx regulon in the event of aberrant beta-barrel outer membrane protein assembly. Mol Microbiol 2010; 75: 103346. 
[27] Alba BM, Gross CA. Regulation of the Escherichia coli sEdependent envelope stress response. Mol Microbiol 2004, 52: 6139.

[28] Raivio TL, Silhavy TJ. Periplasmic stress and ECF sigma factors. Annu Rev Microbiol 2001; 55: 591-624.

[29] Gerken H, Misra R. MzrA-EnvZ interactions in the periplasm influence the EnvZ/OmpR two-component regulon. J Bacteriol 2010; 192: 6271-8.

[30] Mizuno T, Chou MY, Inouye M. A unique mechanism regulating gene expression: translational inhibition by a complementary RNA transcript (micRNA). Proc Natl Acad Sci USA 1984; 81: 1966-70.

[31] Chen S, Zhang A, Blyn LB, Storz G. MicC, a second small-RNA regulator of Omp protein expression in Escherichia coli. J Bacteriol 2004; 186: 6689-97.

[32] Castillo-Keller M, Vuong P, Misra R. Novel mechanism of Escherichia coli porin regulation. J Bacteriol 2006; 188: 576-86.

[33] Douchin V, Bohn C, Bouloc P. Down-regulation of porins by a small RNA bypasses the essentiality of the regulated intramembrane proteolysis protease RseP in Escherichia coli. J Biol Chem 2006; 281: 12253-9.

[34] Bossi L, Figueroa-Bossi N. A small RNA downregulates LamB maltoporin in Salmonella. Mol Microbiol 2007; 65: 799-810.

[35] Johansen J, Eriksen M, Kallipolitis B, Valentin-Hansen P. Downregulation of outer membrane proteins by noncoding RNAs: unraveling the cAMP-CRP- and sigmaE-dependent CyaR-ompX regulatory case. J Mol Biol 2008; 383: 1-9.

[36] Storz G, Opdyke JA, Zhang A. Controlling mRNA stability and translation with small, noncoding RNAs. Curr Opin Microbiol 2004; $7:$ : 140-4.

[37] Vogel J, Papenfort K. Small non-coding RNAs and the bacterial outer membrane. Curr Opin Microbiol 2006; 9: 605-11.

[38] Guillier M, Gottesman S, Storz G. Modulating the outer membrane with small RNAs. Genes Dev 2006; 20: 2338-48.

[39] Chubiz LM, Rao CV. Role of the mar-sox-rob regulon in regulating outer membrane porin expression. J Bacteriol 2011; 193: 2252-60.

[40] George AM, Hall RM, Stokes HW. Multidrug resistance in Klebsiella pneumoniae: a novel gene, ramA, confers a multidrug resistance phenotype in Escherichia coli. Microbiology 1995; 141: 1909-20.

[41] Chollet R, Chevalier J, Bollet C, Pages JM, Davin-Regli A. RamA is an alternate activator of the multidrug resistance cascade in Enterobacter aerogenes. Antimicrob Agents Chemother 2004; 48: 2518-23.

[42] Sulavik MC, Gambino LF, Miller PF. Analysis of the genetic requirements for inducible multiple-antibiotic resistance associated with the mar locus in Escherichia coli. J Bacteriol 1994; 176: 77546.

[43] Seoane AS, Levy SB. Characterization of MarR, the repressor of the multiple antibiotic resistance (mar) operon in Escherichia coli. J Bacteriol 1995; 177: 3414-9.

[44] Bornet $\mathrm{C}$, Chollet R, Malléa M, et al. Imipenem and expression of multidrug efflux pump in Enterobacter aerogenes. Biochem Biophys Res Commun 2003; 301: 985-90.

[45] Viveiros M, Dupont M, Rodrigues L, et al. Antibiotic stress, genetic response and altered permeability of E. coli. PLoS ONE 2007; 2:e365.

[46] Masi M, Pagès JM, Pradel E. Production of the cryptic EefABC efflux pump in Enterobacter aerogenes chloramphenicol-resistant mutants. J Antimicrob Chemother 200; 57: 1223-36.

[47] Ghisalberti D, Masi M, Pagès JM, Chevalier J. Chloramphenicol and expression of multidrug efflux pump in Enterobacter aerogenes. Biochem Biophys Res Commun 2005; 328: 1113-8.

[48] Doménech-Sánchez A, Hernández-Allés S, Martínez-Martínez L, Benedí VJ, Albertí S. Identification and characterization of a new porin gene of Klebsiella pneumoniae: its role in beta-lactam antibiotic resistance. J Bacteriol 1999; 181: 2726-32.

[49] Tran QT, Mahendran KR, Hajjar E, et al. Implication of porins in beta-lactam resistance of Providencia stuartii. J Biol Chem 2010; 285: 32273-81.

[50] Bornet C, Davin-Regli A, Bosi C, Pagès JM, Bollet C. Imipenem resistance of Enterobacter aerogenes mediated by outer membrane permeability. J Clin Microbiol 2000; 38: 1048-52

[51] Rolhion N, Carvalho FA, Darfeuille-Michaud A. OmpC and the sigma(E) regulatory pathway are involved in adhesion and invasion of the Crohn's disease-associated Escherichia coli strain LF82. Mol Microbiol 2007; 63: 1684-700.
[52] Turner AK, Terry TD, Sack DA, Londoño-Arcila P, Darsley MJ. Construction and characterization of genetically defined aro omp mutants of enterotoxigenic Escherichia coli and preliminary studies of safety and immunogenicity in humans. Infect Immun 2001; 69: 4969-79.

[53] Tsai YK, Fung CP, Lin JC, et al. Klebsiella pneumoniae outer membrane porins OmpK35 and OmpK36 play roles in both antimicrobial resistance and virulence. Antimicrob Agents Chemother 2011; 55: 1485-93

[54] Bialek S, Lavigne JP, Chevalier J, et al. Membrane efflux and influx modulate both multidrug resistance and virulence of Klebsiella pneumoniae in a Caenorhabditis elegans model. Antimicrob Agents Chemother 2010; 54: 4373-8.

[55] Lavigne JP, Sotto A, Nicolas-Chanoine MH, et al. Membrane permeability, a pivotal function involved in antibiotic resistance and virulence in Enterobacter aerogenes clinical isolates. Clin Microbiol Infect 2011; 18: 539-45.

[56] O'Regan E, Quinn T, Frye JG, et al. Fitness costs and stability of a high-level ciprofloxacin resistance phenotype in Salmonella enterica serotype enteritidis: reduced infectivity associated with decreased expression of Salmonella pathogenicity island 1 genes. Antimicrob Agents Chemother 2010; 54: 367-74.

[57] Hagan CL, Silhavy TJ, Kahne D. $\beta$-Barrel membrane protein assembly by the Bam complex. Annu Rev Biochem 2011; 80: 189210.

[58] Duguay AR, Silhavy TJ. Quality control in the bacterial periplasm. Biochim Biophys Acta 2004; 1694: 121-34.

[59] Sklar JG, Wu T, Kahne D, Silhavy TJ. Defining the roles of the periplasmic chaperones SurA, Skp, and DegP in Escherichia coli. Genes Dev 2007; 21: 2473-84

[60] Ried G, Hindennach I, Henning U. Role of lipopolysaccharide in assembly of Escherichia coli outer membrane proteins OmpA, OmpC, and OmpF. J Bacteriol 1990; 172: 6048-53.

[61] Voulhoux R, Bos MP, Geurtsen J, Mols M, Tommassen J. Role of a highly conserved bacterial protein in outer membrane protein assembly. Science 2003; 299: 262-5.

[62] Voulhoux R, Tommassen J. Omp85, an evolutionarily conserved bacterial protein involved in outer-membrane-protein assembly. Res Microbiol 2004; 155: 129-35.

[63] Jacob-Dubuisson F, Villeret V, Clantin B, Delattre AS, Saint N. First structural insights into the TpsB/Omp85 superfamily. Biol Chem 2009; 390: 675-84.

[64] Wu T, Malinverni J, Ruiz N, Kim S, Silhavy TJ, Kahne D. Identification of a multicomponent complex required for outer membrane biogenesis in Escherichia coli. Cell 2005; 121: 235-45.

[65] Sklar JG, Wu T, Gronenberg LS, Malinverni JC, Kahne D, Silhavy TJ. Lipoprotein SmpA is a component of the YaeT complex that assembles outer membrane proteins in Escherichia coli. Proc Natl Acad Sci USA 2007; 104: 6400-5

[66] Malinverni JC, Werner J, Kim S, et al. YfiO stabilizes the YaeT complex and is essential for outer membrane protein assembly in Escherichia coli. Mol Microbiol 2006; 61: 151-64.

[67] Kim S, Malinverni JC, Sliz P, Silhavy TJ, Harrison SC, Kahne D. Structure and function of an essential component of the outer membrane protein assembly machine. Science 2007; 317: 961-4.

[68] Vuong P, Bennion D, Mantei J, Frost D, Misra R. Analysis of YfgL and YaeT interactions through bioinformatics, mutagenesis, and biochemistry. J Bacteriol 2008; 190: 1507-17.

[69] Hagan CL, Kim S, Kahne D. Reconstitution of outer membrane protein assembly from purified components. Science 2010; 328: 890-2.

[70] Bennion D, Charlson ES, Coon E, Misra R. Dissection of $\beta$-barrel outer membrane protein assembly pathways through characterizing BamA POTRA 1 mutants of Escherichia coli. Mol Microbiol 2010; 77: 1153-71

[71] Knowles TJ, Jeeves M, Bobat S, et al. Fold and function of polypeptide transport-associated domains responsible for delivering unfolded proteins to membranes. Mol Microbiol 2008; 68: 1216-27.

[72] Clantin B, Delattre AS, Rucktooa P, et al. Structure of the membrane protein FhaC: a member of the Omp85-TpsB transporter superfamily. Science 2007; 317: 957-61

[73] Delattre AS, Saint N, Clantin B, et al. Substrate recognition by the POTRA domains of TpsB transporter FhaC. Mol Microbiol 2011; 81: 99-112.

[74] Delattre AS, Clantin B, Saint N, Locht C, Villeret V, JacobDubuisson F. Functional importance of a conserved sequence motif 
in $\mathrm{FhaC}$, a prototypic member of the TpsB/Omp85 superfamily. FEBS J 2010; 277: 4755-65.

[75] Tellez R Jr, Misra R. Substitutions in the BamA $\beta$-barrel domain overcome the conditional lethal phenotype of a $\Delta$ bamB $\Delta$ bamE strain of Escherichia coli. J Bacteriol 2012; 194: 317-24.

[76] Vinson HM, Gautam A, Olet S, Gibbs PS, Barigye R. Molecular analysis of porin gene transcription in heterogenotypic multidrugresistant Escherichia coli isolates from scouring calves. J Antimicrob Chemother 2010; 65: 1926-35.

[77] Srinivas N, Jetter P, Ueberbacher BJ, et al. Peptidomimetic antibiotics target outer-membrane biogenesis in Pseudomonas aeruginosa. Science 2010; 327: 1010-3.

[78] Wu T, McCandlish AC, Gronenberg LS, Chng SS, Silhavy TJ, Kahne D. Identification of a protein complex that assembles lipopolysaccharide in the outer membrane of Escherichia coli. Proc Natl Acad Sci USA 2006; 103: 11754-9.

[79] Chng SS, Ruiz N, Chimalakonda G, Silhavy TJ, Kahne D. Characterization of the two-protein complex in Escherichia coli responsible for lipopolysaccharide assembly at the outer membrane. Proc Natl Acad Sci USA 2010; 107: 5363-8.

[80] Lou KL, Saint N, Prilipov A, et al. Structural and functional characterization of OmpF porin mutants selected for larger pore size. I. Crystallographic analysis. J Biol Chem 1996; 271: 20669-75.

[81] Dutzler R, Rummel G, Albertí S, et al. Crystal structure and functional characterization of OmpK36, the osmoporin of Klebsiella pneumoniae. Structure 1999; 7: 425-34.

[82] Baslé A, Rummel G, Storici P, Rosenbusch JP, Schirmer T. Crystal structure of osmoporin OmpC from E. coli at 2.0 A. J Mol Biol 2006; 362: 933-42.

[83] Dé E, Baslé A, Jaquinod M, et al. A new mechanism of antibiotic resistance in Enterobacteriaceae induced by a structural modification of the major porin. Mol Microbiol 2001; 41: 189-98.

[84] Thiolas A, Bornet C, Davin-Régli A, Pagès J-M, Bollet C. Resistance to imipenem, cefepime, and cefpirome associated with mutation in Omp36 osmoporin of Enterobacter aerogenes. Biochem Biophys Res Commun 2004; 317: 851-6.

[85] García-Fernández A, Miriagou V, Papagiannitsis CC, et al. An ertapenem-resistant extended-spectrum-beta-lactamase-producing Klebsiella pneumoniae clone carries a novel OmpK36 porin variant. Antimicrob Agents Chemother 2010; 54: 4178-84.

[86] Saint N, Lou KL, Widmer C, Luckey M, Schirmer T, Rosenbusch JP. Structural and functional characterization of OmpF porin mutants selected for larger pore size. II. Functional characterization. J Biol Chem 1996; 271: 20676-80.

[87] Jeanteur D, Schirmer T, Fourel D, et al. Structural and functional alterations of a colicin-resistant mutant of OmpF porin from Escherichia coli. Proc Natl Acad Sci USA 1994; 91: 10675-9.

[88] Simonet V, Malléa M, Pagès JM. Substitutions in the eyelet region disrupt cefepime diffusion through the Escherichia coli OmpF channel. Antimicrob Agents Chemother 2000; 44: 311-5.

[89] Phale PS, Philippsen A, Widmer C, Phale VP, Rosenbusch JP, Schirmer T. Role of charged residues at the OmpF porin channel constriction probed by mutagenesis and simulation. Biochemistry 2001; 40: 6319-25.

[90] Bredin J, Saint N, Malléa M, et al. Alteration of pore properties of Escherichia coli OmpF induced by mutation of key residues in anti-loop 3 region. Biochem J 2002; 363: 521-8.

[91] Nestorovich EM, Danelon C, Winterhalter M, Bezrukov SM. Designed to penetrate: time-resolved interaction of single antibiotic molecules with bacterial pores. Proc Natl Acad Sci USA 2002; 99 : 9789-94.

[92] Danelon C, Nestorovich EM, Winterhalter M, Ceccarelli M, Bezrukov SM. Interaction of zwitterionic penicillins with the OmpF channel facilitates their translocation. Biophys J 2006; 90: 1617-27.

[93] James CE, Mahendran KR, Molitor A, et al. How beta-lactam antibiotics enter bacteria: a dialogue with the porins. PLoS ONE 2009; 4:e5453

[94] Kumar A, Hajjar E, Ruggerone P, Ceccarelli M. Molecular simulations reveal the mechanism and the determinants for ampicillin translocation through OmpF. J Phys Chem B 2010; 114: 9608-16.

[95] Kumar A, Hajjar E, Ruggerone P, Ceccarelli M. Structural and dynamical properties of the porins $\mathrm{OmpF}$ and $\mathrm{OmpC}$ : insights from molecular simulations. J Phys Condens Matter 2010; 22: 454125.

[96] Vidal S, Bredin J, Pagès JM, Barbe J. Beta-lactam screening by specific residues of the OmpF eyelet. J Med Chem 2005; 48: 1395400 .
[97] Misra R, Benson SA. Genetic identification of the pore domain of the OmpC porin of Escherichia coli K-12. J Bacteriol 1988; 170: 3611-7.

[98] Lou H, Chen M, Black SS, et al. Altered antibiotic transport in OmpC mutants isolated from a series of clinical strains of multidrug resistant E. coli. PLoS ONE 2011; 6: e25825.

[99] Davies JK, Reeves P. Colicin tolerance and map location of conjugation-deficient mutants. J Bacteriol 1975; 123: 372-3.

[100] Wandersman C, Delepelaire P. TolC, an Escherichia coli outer membrane protein required for hemolysin secretion. Proc Natl Acad Sci USA 1990; 87: 4776-80.

[101] Delepelaire P. Type I secretion in gram-negative bacteria. Biochim Biophys Acta 2004; 1694: 149-61.

[102] Fralick JA. Evidence that TolC is required for functioning of the Mar/AcrAB efflux pump of Escherichia coli. J Bacteriol 1996; 178: 5803-5.

[103] German GJ, Misra R. The TolC protein of Escherichia coli serves as a cell-surface receptor for the newly characterized TLS bacteriophage. J Mol Biol 2001; 308: 579-85.

[104] Pérez A, Poza M, Fernández A, et al. Involvement of the AcrABTolC efflux pump in the resistance, fitness, and virulence of Enterobacter cloacae. Antimicrob Agents Chemother 2012; 56: 208490.

[105] Minato Y, Siefken RL, Häse CC. TolC affects virulence gene expression in Vibrio cholerae. J Bacteriol 2011; 193: 5850-2.

[106] Platz GJ, Bublitz DC, Mena P, Benach JL, Furie MB, Thanassi DG. A tolC mutant of Francisella tularensis is hypercytotoxic compared to the wild type and elicits increased proinflammatory responses from host cells. Infect Immun 2010; 78: 1022-31.

[107] Ferhat M, Atlan D, Vianney A, Lazzaroni JC, Doublet P, Gilbert C. The TolC protein of Legionella pneumophila plays a major role in multi-drug resistance and the early steps of host invasion. PLoS ONE 2009; 4(11):e7732.

[108] Kadzhaev K, Zingmark C, Golovliov I, et al. Identification of genes contributing to the virulence of Francisella tularensis SCHU S4 in a mouse intradermal infection model. PLoS ONE 2009; 4(5): 5463.

[109] Webber MA, Bailey AM, Blair JM, et al. The global consequence of disruption of the AcrAB-TolC efflux pump in Salmonella enterica includes reduced expression of SPI-1 and other attributes required to infect the host. J Bacteriol 2009; 191: 4276-85.

[110] Bunikis I, Denker K, Ostberg Y, Andersen C, Benz R, Bergström S. An RND-type efflux system in Borrelia burgdorferi is involved in virulence and resistance to antimicrobial compounds. PLoS Pathog 2008; 4(2):e1000009.

[111] Gil H, Platz GJ, Forestal CA, et al. Deletion of TolC orthologs in Francisella tularensis identifies roles in multidrug resistance and virulence. Proc Natl Acad Sci U S A 2006; 103: 12897-902.

[112] Koronakis V, Eswaran J, Hughes C. Structure and function of TolC: the bacterial exit duct for proteins and drugs. Annu Rev Biochem 2004; 73: 467-89.

[113] Schweizer HP. Efflux as a mechanism of resistance to antimicrobials in Pseudomonas aeruginosa and related bacteria: unanswered questions. Genet Mol Res 2003; 2: 48-62.

[114] Koronakis V, Sharff A, Koronakis E, Luisi B, Hughes C. Crystal structure of the bacterial membrane protein TolC central to multidrug efflux and protein export. Nature 2000; 405: 914-9.

[115] Akama H, Kanemaki M, Yoshimura M, et al. Crystal structure of the drug discharge outer membrane protein, OprM, of Pseudomonas aeruginosa: dual modes of membrane anchoring and occluded cavity end. J Biol Chem 2004; 279: 52816-9.

[116] Federici L, Du D, Walas F, et al. The crystal structure of the outer membrane protein VceC from the bacterial pathogen Vibrio cholerae at 1.8 A resolution. J Biol Chem 2005; 280: 15307-14.

[117] Kulathila R, Kulathila R, Indic M, van den Berg B. Crystal structure of Escherichia coli CusC, the outer membrane component of a heavy metal efflux pump. PLoS ONE 2011; 6: e15610.

[118] Andersen C. Channel-tunnels: outer membrane components of type I secretion systems and multidrug efflux pumps of Gram-negative bacteria. Rev Physiol Biochem Pharmacol 2003; 147: 122-65.

[119] Nouwen N, Stahlberg H, Pugsley AP, Engel A. Domain structure of secretin PulD revealed by limited proteolysis and electron microscopy. EMBO J 2000; 19: 2229-36.

[120] Buchanan SK, Smith BS, Venkatramani L, et al. Crystal structure of the outer membrane active transporter FepA from Escherichia coli. Nat Struct Biol 1999; 6: 56-63. 
[121] Locher KP, Rees B, Koebnik R, et al. D Transmembrane signaling across the ligand-gated FhuA receptor: crystal structures of free and ferrichrome-bound states reveal allosteric changes. Cell 1998; 95: 771-8.

[122] Wong KK, Brinkman FS, Benz RS, Hancock RE. Evaluation of a structural model of Pseudomonas aeruginosa outer membrane protein OprM, an efflux component involved in intrinsic antibiotic resistance. J Bacteriol 2001; 183: 367-74.

[123] Andersen C, Hughes C, Koronakis V. Electrophysiological behavior of the TolC channel-tunnel in planar lipid bilayers. J Membr Biol 2002; 185: 83-92.

[124] Masi M, Saint N, Molle G, Pagès JM. The Enterobacter aerogenes outer membrane efflux proteins TolC and EefC have different channel properties. Biochim Biophys Acta 2007; 1768: 2559-67.

[125] Andersen C, Koronakis E, Bokma E, et al. Transition to the open state of the TolC periplasmic tunnel entrance. Proc Natl Acad Sci USA 2002; 99: 11103-8.

[126] Eswaran J, Hughes C, Koronakis V. Locking TolC entrance helices to prevent protein translocation by the bacterial type I export apparatus. J Mol Biol 2003; 327: 309-15.

[127] Werner J, Augustus AM, Misra R. Assembly of TolC, a structurally unique and multifunctional outer membrane protein of Escherichia coli K-12. J Bacteriol 2003; 185: 6540-7.

[128] Masi M, Duret G, Delcour AH, Misra R. Folding and trimerization of signal sequence-less mature TolC in the cytoplasm of Escherichia coli. Microbiology 2009; 155: 1847-57.

[129] Werner J, Misra R. YaeT (Omp85) affects the assembly of lipiddependent and lipid-independent outer membrane proteins of Escherichia coli. Mol Microbiol 2005; 57: 1450-9.

[130] Tokuda H. Biogenesis of outer membranes in Gram-negative bacteria. Biosci Biotechnol Biochem 2009; 73: 465-73.

[131] Li XZ, Poole K. Mutational analysis of the OprM outer membrane component of the MexA-MexB-OprM multidrug efflux system of Pseudomonas aeruginosa. J Bacteriol 2001; 183: 12-27.

[132] Nakajima A, Sugimoto Y, Yoneyama H, Nakae T. Localization of the outer membrane subunit OprM of resistance-nodulation-cell division family multicomponent efflux pump in Pseudomonas aeruginosa. J Biol Chem 2000; 275: 30064-8.

[133] Gerken H, Misra R. Genetic evidence for functional interactions between TolC and AcrA proteins of a major antibiotic efflux pump of Escherichia coli. Mol Microbiol 2004; 54: 620-31.

[134] Vediyappan G, Borisova T, Fralick JA. Isolation and characterization of VceC gain-of-function mutants that can function with the AcrAB multiple-drug-resistant efflux pump of Escherichia coli. J Bacteriol 2006; 188: 3757-62.

[135] Bokma E, Koronakis E, Lobedanz S, Hughes C, Koronakis V. Directed evolution of a bacterial efflux pump: adaptation of the $E$. coli TolC exit duct to the Pseudomonas MexAB translocase. FEBS Lett 2006; 580: 5339-43.

[136] Lobedanz S, Bokma E, Symmons MF, Koronakis E, Hughes C, Koronakis V. A periplasmic coiled-coil interface underlying TolC recruitment and the assembly of bacterial drug efflux pumps. Proc Natl Acad Sci USA 2007; 104: 4612-7.

[137] Ge Q, Yamada Y, Zgurskaya H. The C-terminal domain of AcrA is essential for the assembly and function of the multidrug efflux pump AcrAB-TolC. J Bacteriol 2009; 191: 4365-71.

[138] Weeks JW, Celaya-Kolb T, Pecora S, Misra R. AcrA suppressor alterations reverse the drug hypersensitivity phenotype of a TolC mutant by inducing TolC aperture opening. Mol Microbiol 2010; 75: 1468-83.

[139] Kim HM, Xu Y, Lee M, et al. Functional relationships between the AcrA hairpin tip region and the TolC aperture tip region for the formation of the bacterial tripartite efflux pump AcrAB-TolC. J Bacteriol 2010; 192: 4498-503.

[140] Bavro VN, Pietras Z, Furnham N, et al. Assembly and channel opening in a bacterial drug efflux machine. Mol Cell 2008; 30: 114-21.

[141] Pei XY, Hinchliffe P, Symmons MF, et al. Structures of sequential open states in a symmetrical opening transition of the TolC exit duct. Proc Natl Acad Sci USA 2011; 108: 2112-7.

[142] Tamura N, Murakami S, Oyama Y, Ishiguro M, Yamaguchi A. Direct interaction of multidrug efflux transporter AcrB and outer membrane channel TolC detected via site-directed disulfide crosslinking. Biochemistry 2005; 44: 11115-21.
[143] Higgins MK, Bokma E, Koronakis E, Hughes C, Koronakis V. Structure of the periplasmic component of a bacterial drug efflux pump. Proc Natl Acad Sci USA 2004; 101: 9994-9.

[144] Akama H, Matsuura T, Kashiwagi S, et al. Crystal structure of the membrane fusion protein, MexA, of the multidrug transporter in Pseudomonas aeruginosa. J Biol Chem 2004; 279: 25939-42.

[145] Misra R, Bavro VN. Assembly and transport mechanism of tripartite drug efflux systems. Biochim Biophys Acta 2009; 1794: 81725.

[146] Symmons MF, Bokma E, Koronakis E, Hughes C, Koronakis V. The assembled structure of a complete tripartite bacterial multidrug efflux pump. Proc Natl Acad Sci USA 2009; 106: 7173-8.

[147] Xu Y, Moeller A, Jun SY, et al. Assembly and channel opening of the outer membrane protein in tripartite drug efflux pumps of Gram-negative bacteria. J Biol Chem 2012 ; 287: 11740-50.

[148] Murakami S, Nakashima R, Yamashita E, Matsumoto T, Yamaguchi A. Crystal structures of a multidrug transporter reveal a functionally rotating mechanism. Nature 2006; 443: 173-9.

[149] Seeger MA, Schiefner A, Eicher T, Verrey F, Diederichs K, Pos KM. Structural asymmetry of AcrB trimer suggests a peristaltic pump mechanism. Science 2006; 313: 1295-8.

[150] Murakami S. Multidrug efflux transporter, AcrB--the pumping mechanism. Curr Opin Struct Biol 2008; 18: 459-65.

[151] Aono R, Tsukagoshi N, Yamamoto M. Involvement of outer membrane protein TolC, a possible member of the mar-sox regulon, in maintenance and improvement of organic solvent tolerance of Escherichia coli K-12. J Bacteriol 1998; 180: 938-44.

[152] Barbosa TM, Levy SB. Differential expression of over 60 chromosomal genes in Escherichia coli by constitutive expression of MarA. J Bacteriol 2000; 182: 3467-74.

[153] Martin RG, Rosner JL. Genomics of the marA/soxS/rob regulon of Escherichia coli: identification of directly activated promoters by application of molecular genetics and informatics to microarray data. Mol Microbiol 2002; 44: 1611-24.

[154] Martin RG, Gillette WK, Rosner JL. Promoter discrimination by the related transcriptional activators MarA and SoxS: differential regulation by differential binding. Mol Microbiol 2000; 35: 623-34.

[155] Zhang A, Rosner JL, Martin RG. Transcriptional activation by MarA, SoxS and Rob of two tolC promoters using one binding site: a complex promoter configuration for tolC in Escherichia coli. Mol Microbiol 2008; 69: 1450-5.

[156] Eguchi Y, Oshima T, Mori H, et al. Transcriptional regulation of drug efflux genes by EvgAS, a two-component system in Escherichia coli. Microbiology 2003; 149: 2819-28.

[157] Groisman EA. The pleiotropic two-component regulatory system PhoP-PhoQ. J Bacteriol 2001; 183: 1835-42.

[158] Cohen SP, Levy SB, Foulds J, Rosner JL. Salicylate induction of antibiotic resistance in Escherichia coli: activation of the mar operon and a mar-independent pathway. J Bacteriol 1993; 175: 785662.

[159] Demple B. Redox signaling and gene control in the Escherichia coli soxRS oxidative stress regulon-a review. Gene 1996; 179: 537.

[160] Rosner JL, Dangi B, Gronenborn AM, Martin RG. Posttranscriptional activation of the transcriptional activator Rob by dipyridyl in Escherichia coli. J Bacteriol 2002; 184: 1407-16.

[161] Rosenberg EY, Bertenthal D, Nilles ML, Bertrand KP, Nikaido H. Bile salts and fatty acids induce the expression of Escherichia coli AcrAB multidrug efflux pump through their interaction with Rob regulatory protein. Mol Microbiol 2003; 48: 1609-19.

[162] Nikaido E, Yamaguchi A, Nishino K. AcrAB multidrug efflux pump regulation in Salmonella enterica serovar Typhimurium by RamA in response to environmental signals. J Biol Chem 2008; 283: 24245-53.

[163] Bailey AM, Ivens A, Kingsley R, Cottell JL, Wain J, Piddock LJ. RamA, a member of the AraC/XylS family, influences both virulence and efflux in Salmonella enterica serovar Typhimurium. J Bacteriol 2010; 192: 1607-16.

[164] Sulavik MC, Houseweart C, Cramer C, et al. Antibiotic susceptibility profiles of Escherichia coli strains lacking multidrug efflux pump genes. Antimicrob Agents Chemother 2001; 45: 1126-36.

[165] Swick MC, Morgan-Linnell SK, Carlson KM, Zechiedrich L. Expression of multidrug efflux pump genes acrAB-tolC, mdfA, and norE in Escherichia coli clinical isolates as a function of fluoroquinolone and multidrug resistance. Antimicrob Agents Chemother 2011; 55: 921-4. 
[166] Alekshun MN, Levy SB. The mar regulon: multiple resistance to antibiotics and other toxic chemicals. Trends Microbiol 1999; 7: 410-3.

[167] Piddock LJ. Clinically relevant chromosomally encoded multidrug resistance efflux pumps in bacteria. Clin Microbiol Rev 2006; 19: 382-402.

[168] Rosner JL, Martin RG. An excretory function for the Escherichia coli outer membrane pore TolC: upregulation of marA and soxS transcription and Rob activity due to metabolites accumulated in tolC mutants. J Bacteriol 2009; 19: 5283-92.

[169] Lee HH, Molla MN, Cantor CR, Collins JJ. Bacterial charity work leads to population-wide resistance. Nature 2010; 467: 82-5.

[170] Ricci V, Tzakas P, Buckley A, Piddock LJ. Ciprofloxacin resistant Salmonella enterica serovar Typhimurium strains are difficult to select in the absence of AcrB and TolC. Antimicrob Agents Chemother 2006; 50: 38-42.

[171] Yan M, Sahin O, Lin J, Zhang Q. Role of the CmeABC efflux pump in the emergence of fluoroquinolone-resistant Campylobacter under selection pressure. J Antimicrob Chemother 2006; 58: 1154-9.
[172] Quinn T, O’Mahony R, Baird AW, Drudy D, Whyte P, Fanning S Multi-drug resistance in Salmonella enterica: efflux mechanisms and their relationships with the development of chromosomal resistance gene clusters. Curr Drug Targets 2006; 7: 849-60.

[173] Andersson DI, Hughes D. Antibiotic resistance and its cost: is it possible to reverse resistance? Nat Rev Microbiol 2010; 8: 260-71.

[174] Martínez JL, Rojo F. Metabolic regulation of antibiotic resistance. FEMS Microbiol Rev 2011; 35: 768-89.

[175] Wiedenbeck J, Cohan FM. Origins of bacterial diversity through horizontal genetic transfer and adaptation to new ecological niches. FEMS Microbiol Rev 2011; 35: 957-76.

[176] Bolla JM, Alibert-Franco S, Handzlik J, et al. Strategies for bypassing the membrane barrier in multidrug resistant Gramnegative bacteria. FEBS Lett 2011; 585: 1682-90.

[177] Giamarellou H. Multidrug-resistant Gram-negative bacteria: how to treat and for how long. Int J Antimicrob Agents 2010; 36: S50-4.

[178] Hurdle JG, O'Neill AJ, Chopra I, Lee RE. Targeting bacterial membrane function: an underexploited mechanism for treating persistent infections. Nat Rev Microbiol 2011; 9: 62-75.

Received: December 05, 2012

Revised: February 01, 2013

Accepted: February 03, 2013

(C) Masi and Pages; Licensee Bentham Open.

This is an open access article licensed under the terms of the Creative Commons Attribution Non-Commercial License (http://creativecommons.org/licenses/ by-nc/3.0/) which permits unrestricted, non-commercial use, distribution and reproduction in any medium, provided the work is properly cited. 